\title{
Development and fabrication of Alpha Stirling Engine
}

\author{
Vishal Gehlot ${ }^{1}$, Abhinay Nigam ${ }^{2}$, Kunal Marmat ${ }^{3}$ \\ ${ }^{1}$ (Mechanical Engineering Department, MITS, Ujjain M.P. India) \\ ${ }^{2}$ (Mechanical Engineering Department, MITS, Ujjain M.P. India) \\ ${ }^{3}$ (Mechanical Engineering Department, SGSITS, Ujjain M.P. India)
}

\begin{abstract}
This paper describes a new approach to Develop and fabrication of an Alpha Stirling engines with the goal of building a working prototype. The Stirling cycle is recast as a dynamic system where control design tools and techniques can be applied to determine optimal manufacturable parameters for the engine. This Alfa type Stirling engine constructed by two unused Kirloskar diesel engine as one is for power cylinder and another is for cooled cylinder. Both are coupled by two ways - one is flexible coupling and another is injector holder to heat exchanger joining by pressure pipe. This type of engine has a high power to volume ratio but has technical problems due to the usually high temperature of the hot piston and the durability of its seals. The paper proposes the way to build and utilize Stirling engine for the green energy applications. The research on Stirling engine is being increased, many inventions reveals the suitability of engine for low power applications that includes an alternative for engines in industries. Finally, the Stirling engine model is experimentally verified.
\end{abstract}

Keywords: Alpha Stirling Engine, Regenerative heat exchanger, Design and fabrication, Parts and Components, Further scope, Implementations,

\section{Introduction}

Stirling engine provide clean, reliable, mechanical power when provided only with a temperature gradient. Unlike combustion engine, Stirling engines do not require a distillate fuel like gasoline and can therefore streak on heat from any source such as geothermal, solar, biomass or nuclear vitality. The Stirling cycle operates by shuttling a compressed gas between two chambers separated by a lightweight piston. The engine cycle is thrust by the transport of heat across a static temperature difference either side of the chamber. [1] Stirling Engine is a heat engine operating by cyclic compression and expansion of air or other gas, the working fluid, at different temperature levels such that there is a net conversion of heat energy to mechanical work.

\section{Alpha Stirling engine}

An alpha Stirling contains two power pistons in separate cylinders, one hot and one cold. The hot cylinder is situated inside the high temperature heat exchanger and the cold cylinder is situated inside the low temperature heat exchanger. This type of engine has a high power-to-volume ratio but has technical problems due to the usually high temperature of the hot piston and the durability of its seals. In practice, this piston usually carries a large insulating head to move the seals away from the hot zone at the expense of some additional dead space.

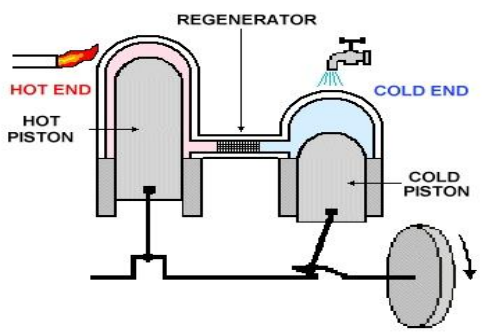

Figure 1: Alpha Stirling engine

\section{Problem statement}

We have tried to develop an alpha type Stirling engine by coupling two diesel engines at a phase difference of 90degree. Thus we have tried to develop an engine that is:

- Readily available in marked and thus easily replicable.

- The spares of engine would be easily available. The manufacturing difficulties that arise in developing a new engine are avoided.

- The engine can be easily reproduced in larger numbers if the experimental trials are successful. 


\section{Design of Engine Components}

The following are the sub-assemblies that are required either to search a component of similar dimensions or to fabricate.

\section{Design of frame-}

The frame is used to support piston cylinders, flywheel connected shaft and other rotating parts. Frame is bought to its shape with the help of lathe and other tools and circular holes are drilled by means of drilling machines. Bearings are provided inside the supports to hold horizontal shaft.

\section{Design of piston-}

The piston can be constructed of cold rolled steel to ensure its thermal properties for the hot cylinder assembly. This plays an important role as in case of tolerances between the piston and cylinder walls. To have a greater efficiency the surface finish should be very high so that losses will be minimum, but due to machining complication it's good to buy a machined product which suits the design requirements.

\section{Design of cylinders-}

Two cylinders (Hot and cold chambers) are of same dimension. It can be fabricated using cold forging or casting. Due to high surface finish criteria it is forged then finishing operation is done through internal grinders.

\section{Parts and components}

Diesel engine -Here we use two different unused Kirloskar engine. One is for hot and another for cold.

Regenerator - Regenerator is a heat exchanger designed by optimized parameters. This is fabricated from mild steel block. It can work as a regenerative heat exchanger.

Flexible coupling-Flexible coupling is used to connect two shafts together at their ends for purpose of transmitting power.

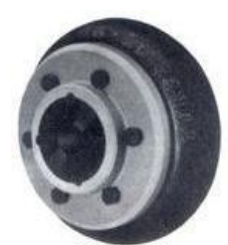

(a)

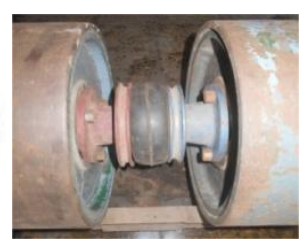

(b)

Fig-2 (a) Flexible coupling (b) flywheel with flexible coupling

High pressure pipes- High pressure tubes of alloy are used for connecting heat exchanger to the cylinder of engine.

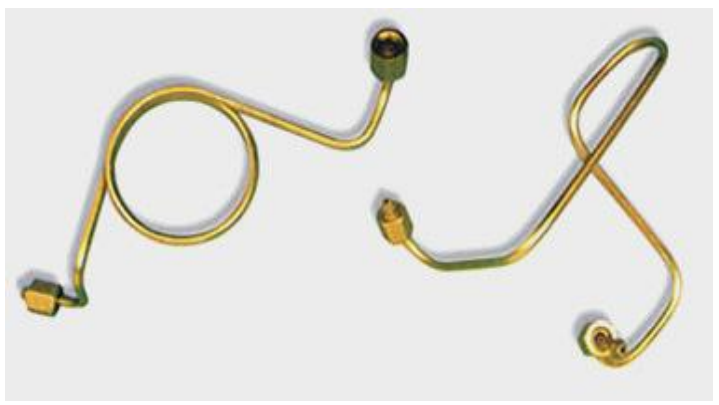

Fig.3 High pressure pipes

Hexagonal adapters - Adapter of hexagonal end are used for connecting heat exchanger to the pressure pipe through the injector of engine.

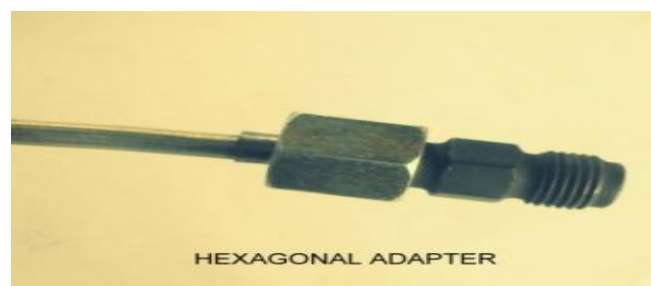

Fig-4 Hexagonal adapter 


\section{Experimental validation and characterization}

Both cylinder pistons are connected on 900 phase angle with the help of flexible coupling. The heat exchanger is heated heat exchanger. The engine consists of four thermodynamic processes action on the working fluid: which are as - expansion, transfer, contraction and transfer. When hot gas is transferred to the cool cylinder, it is first driven through the regenerator (heat exchanger), where a portion of the heat is deposited from LPG directly up to red hot condition. The temperature of heat exchanger reached over $6000 \mathrm{C}$. First cylinder heated and another kept too cooled via water drops. After heated at certain level engine has cranked manually by hand cranking. When the cool gas is transferred back, this heat is reclaimed; thus the regenerator "pre heats" and "pre cools" the working gas, dramatically improving efficiency. Regardless of the function the heat exchanger fulfills, in order to transfer heat the fluids involved must be at different temperatures and they must come into thermal contact. Heat can flow only from the hotter to the cooler fluid. [2]

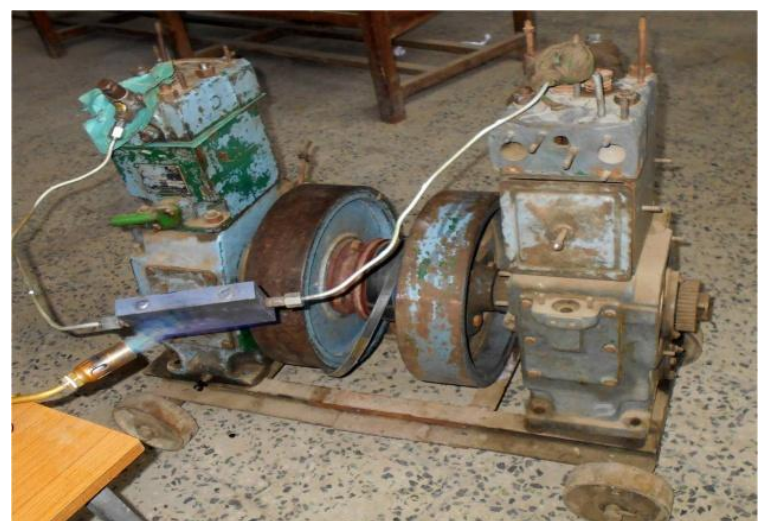

Fig-5 Experimental trial

\section{Further Scope}

The output of the engine is less than what is been expected it can be further increased by following ways.To build the productivity fins are given over the chamber so the heat exchange rate will be high when contrasted with ordinary chambers By working at different temperatures we can acquire different efficiencies. Likewise Stirling engines can use the power of the sun to give the vital vitality to the system with the assistance of micro controllers. The fundamental motivation behind the undertaking served to advance the utilization of Stirling Engines in 'environmentally friendly power vitality' applications. Because of the high hypothetical efficiencies of Stirling engines they are a prime contender for future sun based vitality research. Sun powered controlled Stirling motors are presently financially accessible up to $25 \mathrm{~kW}$ of generating limit.

\section{Implementation of Stirling engine for Industrial problems}

Stirling engines can run directly on any available heat source, not just one produced by combustion, so they can run on heat from solar, geothermal, biological, nuclear sources or waste heat from industrial processes.

1. Electricity production: By coupling the dynamo with Stirling engine, above mentioned heat source engine is made to run and electricity is produced

2. Alternate for motors: In industries, instead of using motors the pumps, compressors and low power machines are directly run with the help of Stirling engine by utilizing waste heat.

3. Dual power output to increase engine performance: Waste heat is easily harvested (compared to waste heat from an internal combustion engine) making Stirling engines useful for dual-output heat and power systems.

4. Fuel saver: Like Petrol-Battery hybrid cars, Petrol- Stirling or diesel-Stirling hybrid vehicles can be used

5. Increase in engine efficiency: Stirling engine are used in automobiles to operate Air conditioning and various pumps. So we can increase the main engine efficiency

6. Alternate for Air conditioner: engine is extremely flexible which can be used as CHP (combined heat and Power) in winters and as coolers in summer. [3]

\section{References}

[1]. Eric J. BarthP. I., Mark Hofacker "Dynamic Modeling of a Regenerator for the Control Based Design of Free-Piston Stirling Engines" Department of Mechanical Engineering Vanderbilt University, Nashville, TN37212

[2]. S.Chaugaonkar.,V.Gehlot, V. Parashar, "Design and Fabrication of Regenerative Heat exchanger For Alpha Stirling Engine" International Journal of Advanced Mechanicalm Engineering.ISSN 2250-3234 Volume 4, Number 7 (2014), pp. 829-837

[3]. Dinesh.K, Gowtham Raj.R, Naresh.M, Rakesh.N, Sriram.R, "Design and Fabrication of Low Cost Stirling Engine For Low Duty Industrial Applications" International Journal of Scientific \& Technology Research Volume 3, Issue 3, March 2014 ISSN 2277 8616

[4]. Christian Falk, "Predicting performance of regenerative heat exchanger", Lund University, Lund, Sweden 